\title{
Introduction
}

\section{Autobiography, Ethnography, and History: A Model for Reading}

\section{Redefining Autobiography}

When does cultural description further self-expression and when does it defeat autobiographical purpose? This book traces the complicated relationship between identity, culture, and language; between the desire to speak autobiographically and the pressures ethnography exerts upon this desire. Cookbooks, labor histories, and edited narratives of women working as midwives and healers may not seem to qualify as autobiographies. Rather than foregrounding the "I," they appear to celebrate a collective, focusing on ethnic culinary traditions, on the medical services midwives and healers provide in poor communities, or on the struggles of labor activists to improve working conditions for their members. Yet, as I try to show here, the women who speak in these books use the languages of folklore, of social critique, and of historical tribute to speak on their own behalf as well. Their personal narratives manage to be socially engaged without submerging individual voice in collective history.

Choosing books with such titles as The Good Life: New Mexico Traditions and Food, All for One, and La Partera: Story of a Midwife for a study of autobiography obviously implies arguing to expand the definition of the genre. ${ }^{1}$ Reading autobiographical gestures in narratives that are not confessional or even "literary" also implies locating such impulses historically. If the desire to make the self in language is a constant, the linds of 
languages available to people change across time, culture, and region. ${ }^{2}$ Writing a distinctive "I," for ethnic Americans particularly, often means writing against the grain: of an East Coast publishing establishment that defines "Mexican" through the writings of white traveler-surveyors from New England who were more interested in mapping what they successively called "the "frontier" and "the Golden State" than in reading the personal narratives of "native Californians $;{ }^{3}$ of nativist accounts of American identity that present "Jew-town" as a strange and exotic setting, while simultaneously offering the assimilationist bildungsroman as the only literary template by which immigrant autobiographers could gain access to publishing, ${ }^{4}$ of a century of editorial insistence that the distinctive personal histories of black Americans are valuable only insofar as they illustrate a unitary sociological "them"; of critical and theoretical accounts of American women's autobiographies that either celebrate "community" across diverse ethnic texts, or else leave out ethnic women altogether. ${ }^{5}$

In the chapters that follow, I trace the forms this generalizing tendency takes in a number of different discursive and historical circumstances, as a means of contextualizing the strategies women autobiographers use to insist on their own self-distinction. In a recent essay on the politics of contemporary Chicana literature, Sonia Saldívar-Hull argues that Mexicana readers must "look in nontraditional places for our theories: in the prefaces to anthologies, in the interstices of autobiographies, in our cultural artifacts, our cuentos, and ... in the essays published in marginalized journals." 6 My reading strategy, like Saldívar-Hull's, looks to nontraditional kinds of autobiography in order to demonstrate the range of rhetorical maneuvers writers use to insert their presence into contexts that discourage sustained autobiographical voicing. At the same time, this method enumerates what feminist critic Sidonie Smith has recently called "the pressure points" women in turn place on "traditional autobiography as it presses [them] into a specific kind of autobiographical subject." 7 And I consider as well how current critical readings of such nontraditional autobiography often reproduce the generalizing pressures the writers have experienced, how such readings embody what Sidonie Smith and Julia Watson characterize as the propensity to "see the colonized as an amorphous, generalized collectivity." 8

Thus this study questions recent theories that celebrate the self-inrelation at the same time as they slight forms of subjectivity that empha- 
size the distinctive qualities of the self. For instance, some critics of ethnic autobiography too easily conflate a cultural plural (a "we" derived out of and taken for granted by the disciplines of ethnography, sociology, and anthropology) with this discrete "I," just as some feminist scholars argue that a gendered "we" defines the subject in autobiographical writing by women. My own reading practice follows Sau-ling Wong's recommendation, in Reading Asian American Literature, to work toward "a scrupulous grappling with textual complexities" as a means of avoiding ahistorical generalizations about the feminine subject. ${ }^{9}$ The focus of this book on the particularizing gestures of a number of women autobiographers is, of course, first a response to what I perceive to be the writers' own impulses to authorize the self in discursive contexts that discourage self-distinction. But it is also a response to the direction of current theorizing about personal narrative, which makes the need to specify a particularly urgent theoretical project in and of itself.

\section{Rethinking the Politics of "Accommodation"}

Here I would like to illustrate my own argument for specificity by way of the folkloric work of two Hispana writers who published at midcentury in New Mexico. The memoirs of Fabiola Cabeza de Baca and Cleofas Jaramillo exemplify the relation between autobiographic impulse and ethnographic necessity. Charting the development of the self, Cabeza de Baca's We Fed Them Cactus (1954) and Jaramillo's Romance of a Little Village Girl (1955) describe in the process the communal traditions and cultural practices upon which identity is grounded..$^{10}$ Before publishing their more sustained autobiographical narratives, however, both Cabeza de Baca and Jaramillo wrote a series of cookbooks - books which describe not only food but folklore, books which reproduce recipes along with memories of holiday preparations, religious events, and family celebrations. It is these books, I would argue, that enable the more self-possessed prose of the later memoirs.

Like the subtlety of ethnic women's self-presencing strategies more generally, which take place within the context of (variously) inhospitable publishing circumstances, the self-disclosing gestures these narratives contain are articulated against the grain of a language that discourages them, a language made famous by expatriates like D. H. Lawrence and folklorist- 
writers like Mary Austin, who eulogized the turquoise skies of New Mexico and lamented, with unctuous aesthetic relish, its "ever-declining" civilization. As Genaro Padilla argues, such romanticizing language, ostensibly celebratory of the land and its native inhabitants, actually deprived them of speech, "setting them into the sediment of the earth instead of relating to them as social subjects, mystifying and mythifying their cultural practices, reducing their social history, ignoring their individuality." 11 The grandiloquent prose of writers like Lawrence and Austin is clearly meant to pay homage to the grand Southwestern vistas the visitors found so inspiring, yet the romanticism of their writings suggests that their gaze was at times more enthusiastic than discriminating. In their preference for panoramic overview rather than close reading, their eye for the large outline rather than for fine detail, they tend to the sweeping statements that characterize ethnographic narrative more generally. In their capacity for overstatement, that is, the eulogies of these newcomers to New Mexico at midcentury typify other writing by nonnatives about natives, their own literary language borrowing from the disciplines of sociology and anthropology in its tendency to objectify people and to exoticize their cultural practices. And while the particular forms this ethnographic model takes vary with historical circumstance, its implications for autobiography are regrettably constant: to reduce the nuanced cadences of particular voices to one generic note.

In the face of the literary establishment's definition of Southwestern narrative, the cookbooks Jaramillo and Cabeza de Baca published provided them with a suitably nonthreatening framework within which to work toward self-expression. ${ }^{12}$ Presenting itself in relation to ethnic community rather than claiming center stage, the authorial " $\mathrm{I}$ " in these texts is a modest presence. But if the authors' voices are unobtrusive, as they slip quietly in and out of recollections that mark familial and racial affiliation, both Cabeza de Baca and Jaramillo claim identities for themselves in their culinary narratives, which act as a kind of prelude to the more sustained autobiographical voices of the later memoirs.

Critic Ramón Saldívar argues that "contemporary Chicano narratives and other forms of novelistic discourse are ... self-consciously crafted acts of social resistance," ${ }^{13}$ but close reading of apparently accommodationist texts reveals oppositional voicing there as well. As the Personal Narratives Group argue, "many women's personal narratives unfold within the frame- 
work of an apparent acceptance of social norms and expectations but nevertheless describe strategies and activities that challenge those same norms." ${ }^{14}$ Cabeza de Baca's The Good Life, for example, exploits this subtle strategy. Announcing in her preface that "the fondest memories of my life are associated with the people among whom I have worked," she inserts herself into a text that does not really require her presence, establishing life history at the center of a book ostensibly dedicated to celebrating a communal idea of culture. Situations that discourage autobiographical voicing will of necessity demand such rhetorical maneuvering. Open resistance may be the endpoint in a literary teleology that assumes that the most advanced political maneuver is always the most explicit one. Yet, as Raymund Paredes suggests in his own account of Chicano literature, "The members of an ethnic or racial minority, deprived of material goods and sophisticated technology, rely on their wits to survive in an oppressive society." 15 In contexts that make plain speaking impossible, writers still manage to speak their mind.

I am not suggesting an either/or interpretive framework (either "progressive," "multi-voiced," "dialogic," and "resistive" or "conservative," "univocal," "monologic," and "accommodating"). To my mind, most authors do not either simply "re-elaborate" or simply "rewrite" "the received behavioral script of the rhetorically well-defined American self," as William Boelhower suggests in a recent essay on ethnic autobiography in the United States. ${ }^{16}$ Rather, their texts both exert pressure upon and must contend with the languages available to them. Determined to express their own presence in such contexts often means, as I have suggested, that such authors have to speak "on a bias," across the grain of narratives explicitly dedicated to ethnography, to history, or to cooking.

In the cookbooks of Cabeza de Baca, as in the works of many of the other women I consider in this project, resistance is often masked. Autobiographers like Cleofas Jaramillo, Onnie Lee Logan, ${ }^{17}$ and Rose Schneiderman make use of metaphors that sustain a characteristically feminine humility, yet a closer look at the rhetorical patterns that govern their narratives reveals a critical awareness that is often at odds with the status quo. Rose Pesotta likens her organizing work for the International Ladies' Garment Workers Union to "housekeeping," but when this disclaimer precedes her request to an overconfident young volunteer to sweep the floor of the common room, we can see her remark for what it is: a directive 
designed to quash his masculine arrogance. Likewise, Rose Schneiderman's coy reference to her diminutive stature only makes her account of herself as the first woman representative on a federal labor committee look a more grandiose accomplishment. If these women advance their arguments cautiously - obliquely, circuitously, through repetition and accretion rather than direct appeal-their criticism is ultimately no less pointed for being articulated in coded form.

Nor are their own interests as autobiographers less marked for being developed in texts ostensibly dedicated to historical documentation. Or to cultural inquiry: I have suggested that people make their opportunities where they find them, and for women of color, especially, such openings have often taken shape in an ethnographic publishing context that ignores the specificities of individual voices in order to draw general, and abstract, claims about the way "culture" operates. ${ }^{18}$ Whether these claims are advanced as explicitly anthropological, as sociological studies premised on a distinction between "domestic" and "foreign" communities, or as "purely" literary, the outcome is the same. Comprehensive patterns, not the particularities of inflection, are the object, and those under examination are characterized-if not caricatured-as cultural icons, exemplars of traditions left over from primitive times, racialized identities where race is not one variable in a wider field but an absolute value, sufficient in and of itself. Many of the collaborative texts I discuss in Part 3 of this book take shape in this context, one in which the editorial agenda, despite affirmations to the contrary, attempts to rewrite the autobiographical particulars of the speaker as representative of a tradition-a tradition generally styled as an anachronism from some vaguely pretechnological time. When she associates the interest of Jesusita Aragón's life history with her status as "the last of the traditional, Hispanic midwives in the area," ${ }^{19}$ editor Fran Leeper Buss provides a case in point. For Buss, Aragón functions as a cultural icon, a museum piece who evokes memories of an earlier, "lost" era. The same desire to return to a presumably simpler, bucolic scene characterizes the relation between editor and speaker in Motherwit: An Alabama Midwife's Story, another interracial collaboration. Despite Onnie Lee Logan's numerous references to the thriving practices of other midwives, editor Katherine Clark persists in styling this "granny midwife" as "the last ... in Mobile and one of the last in Alabama" (xiii). Once again autobiography works in the service of ethnography as Logan's discrete his- 
tory becomes, in the editor's introduction, the history of all human evolution and change; "performing a service as old as the human race," she is described as moored by the currents of time, "caught in the flux of a changing culture . .. an unusual victim of historical "progress' " (xiii).

The pressures of ethnographic discourse upon autobiographers are not exerted solely on those in joint publishing ventures, nor are they produced only by editorial agenda. In "Autobiography as Guided Chinatown Tour? Maxine Hong Kingston's The Woman Warrior and the Chinese American Autobiographical Controversy," Sau-ling Wong argues that writing for an interethnic audience encourages ethnographic representation that often ends by commodifying cultural practice:

Removed from Chinese culture in China by their ancestors' emigration, American-born autobiographers may still capitalize on white curiosity by conducting the literary equivalent of a guided Chinatown tour: by providing explanations on the manners and mores of the Chinese American community from the vantage point of a "native." 20

This kind of autobiography, which forces the subject to serve as cultural ambassador for an audience eager for a peek at "exotic" rites and "foreign" practices, defines the field so that even those personal narratives that refuse to act as literary tour guides may nevertheless get read as such. Wong goes on to suggest that "from an intraethnic point of view, the writing of autobiography may be valued as a means of preserving memories of a vanishing way of life, and hence of celebrating cultural continuity and identity; in an interethnic perspective, however, the element of display, whether intentional or not, is unavoidable." 21 Yet the very "involuntary intertextuality" that she so acutely identifies as characteristic of the reception of Chinese American narratives-and that, I would argue, is typical of other ethnic autobiographical traditions as well-may inform intraethnic readerships too. ${ }^{22}$ Or, rather, anyone whose writing gets marketed under this ethnographic rubric will inevitably have to contend with its tradition of objectification and its tendency to hurry the postmortems on those cultures diagnosed as dying or in distress. ${ }^{23}$ And, given the imperial frame of reference within which this language has its origin-and continues to flourish-virtually any effort to define the self in relation to ethnic community runs the risk of being glossed by others as more a cultural sign than an autobiographical presence. 


\section{All for One and One for All: \\ Complicating the Relationship \\ Between Affiliation and Self-Distinction}

Nevertheless, identity (likeness?) cannot be defined without reference to difference, cannot be theorized independently of class, of geography, of gender —or of ethnicity. Poststructuralists have insisted on the contingent nature of the "I," but they have generally chosen as illustrations the classic literary examples: Woolf, Flaubert, Balzac, Shakespeare. ${ }^{24}$ For the women considered in this study, however, writers neither celebrated nor even marginal to canonical literature, so much as "extra-literary," the cultural "we" and the autobiographical "I" always stand in relation. And despite historical situations which trivialize their contributions as women and language contexts which discourage self-representation, they rely on a conjunction of singular and collective voicing in order to develop subjectivity.

The following very different autobiographical introductions-the first from Zora Neale Hurston, the second from Jade Snow Wong-demonstrate the complicated relation between affiliation and distinction:

I maintain that I have been a Negro three times-a Negro baby, a Negro girl and a Negro woman. Still, if you have received no clear cut impression of what the Negro in America is like, then you are in the same place with me. There is no The Negro here. Our lives are so diversified, internal attitudes so varied, appearances and capabilities so different, that there is no possible classification so catholic that it will cover us all, except My people! My people! ${ }^{25}$

By turns, the family coaxed and ridiculed the recalcitrant member, but Jade Snow grew more grimly stubborn as their pressure became greater. Thus in the one Wong family picture complete with its in-laws, the camera recorded Jade Snow, defiant and tense, with the only head of straight feminine hair in the group of curly-topped, relaxed, smiling faces. ${ }^{26}$

Zora Neale Hurston's "I" may initially look bolder on the page than the more oblique self-presentation Jade Snow Wong offers readers, but the first-person pronouncements of Dust Tracks and the "she" who is described for us in Fifth Chinese Daughter equally defy easy attempts at classification. Despite the ambivalence with which they invoke their affiliations with racial community, family, and female networks, both writers 
insist on their own self-distinctiveness precisely in relation to these ties that bind.

This desire to frame the self as unique-even iconoclastic-has been considered by traditional autobiography criticism to be one of the essential characteristics of personal narrative. ${ }^{27}$ Yet this very effort to maintain difference-in relation to race, to family, to sex-has brought down upon both Hurston and Wong the most severe admonishments, albeit in different critical contexts. Hurston has often been indicted as unwilling to engage the facts of racial politics in her self-revelatory writings, and her insistence on a portraiture that defies community affiliation has been labeled as self-deceiving and untruthful to the spirit of a genre dedicated to uncovering the "truth" about identity. ${ }^{28}$ Moreover, Frank Chin has chastised Wong for choosing to write autobiographically, defining the genre as unalterably Christian, white, and Western, and thus false to the experience of the Chinese in the United States. ${ }^{29}$

Assigning an historical truth-value to personal narrative accords it privileged status as a "record" and denies that it is subject to the general rules of language, to be applied equally to literature and documentary. Yet in calling attention to the historical context within which both books are produced, these comments do serve an important critical function. The responses of blacks to the Second World War, conceived as either a patriotic or an imperialist project, certainly inform Hurston's book, despite her inability, because of publishing strictures, to invoke it explicitly. And though Chin's sanctions against Wong are derisively framed, his insistence on the relation between history and literature underscores how crucial it is to rewrite a historical record which to a large extent still remains whitewashed. Memory often provides a viable alternative to such a history, as autobiography theorist Françoise Lionnet suggests in her discussion of Hurston. ${ }^{30}$ The association between autobiography and history, then, should not be reduced to a question of foreground versus background; texts are informed, not determined, by history.

Linked to this issue of text and context is another question of boundaries: of "inside" and "outside" and the relation between them. If the criticisms of Hurston and of Wong tend to overstate the degree to which the subjects of Dust Tracks and Fifth Chinese Daughter celebrate iconoclasm and resist racial identification, ${ }^{31}$ their insistence on the relation between 
the "I" and the "we" does raise one of the crucial questions of contemporary autobiography criticism, particularly of what are called (as if white authors are somehow raceless) "ethnic" texts. ${ }^{32}$ Just how is the self of personal narrative, as it works toward self-formation, engaged in affiliation as well? To what degree is the "us," described by Hurston as at once irrelevant to the "me" and yet implicated in its development, the subject of autobiography? To what extent is Wong's "membership" the focus of a narrative which ostensibly refuses its sanctuary?

With respect to the narratives this study foregrounds, I would argue that in privileging the "we" over the "I," recent responses which celebrate the collective in the theory and criticism of ethnic literature, autobiography, and gender studies run the risk of oversimplifying the relation between distinction and affiliation as surely as did the ethnographic publishing conditions under which these books were first produced ${ }^{33}$ My own concern is to move toward redressing this balance by retrieving those impulses toward self-presencing which I believe remain an essential characteristic of life writings. But I wish to hold to the notion of "balance" here, not to reinstate the idea of the isolationist "I" which lies at the heart of traditional definitions of the autobiographical canon. Rather than fix the subject of a given text as either illustrative of a privileged self, distinguished from others in bold relief, or as an example of the "we" that is metonymic of a collective, identity might more effectively be appraised with reference to a continuum. This flexible model has the advantage of supporting multiple self-positionings that can provide critiques of bipolar theories. Notwithstanding their different discursive and historical contexts, for instance, the texts I consider here all challenge conventional notions of the genre. Politically engaged, they tend to frame consciousness less as contemplative than as involved with social conditions, community affiliations, and historical circumstances. But drawing connections between "me" and "us" and maintaining distinctions between "us" and "them"- the latter as much of a concern as the former for the writers and speakers discussed in the following chapters-does not preclude the kind of self-formation traditionally considered autobiographical. The practice of self-contextualization, that is, does not prevent people from speaking their own idiosyncratic selves into textual existence. On the contrary, as I have already suggested in my comments on Fabiola Cabeza de Baca's The Good Life, 
acknowledgment of affiliation often provides the basis from which the "I" authorizes herself to speak.

\section{Revising the Subject of Traditional Autobiography}

I am interested here in amplifying such strategies toward self-presencing. My work could not have developed, however, without the two decades of committed attention to revising and enriching that earlier model. Susan Friedman cites Regina Blackburn as defining "The "self" of black autobiography" as " 'a conscious political identity, drawing sustenance from the past experience of the group." "34 This contextualization is a crucial revision of earlier versions of subjectivity which refused to recognize how the "I" is implicated and informed by circumstance. Similarly, Arnold Krupat's description of Native American autobiography as a tradition in which "the self most typically is not constituted by the achievement of a distinctive, special voice that separates it from others, but, rather, by the achievement of a particular placement in relation to the many voices without which it could not exist," 35 if an overgeneralized critical portrait, corrects a monochrome version of personal narrative that defines only the self of the writings of the Puritans and their descendants-Jonathan Edwards, Benjamin Franklin, Henry Adams-as achieving autobiographical distinction. ${ }^{36}$

My own study builds upon this reevaluation of personal narrative. Critics like Blackburn and Krupat, as well as other scholars-William Andrews, Françoise Lionnet, Genaro Padilla, Joanne Braxton, Hertha Wong-have already responded to constricted definitions of the genre by delineating traditions of their own using more politically and historically engaged criteria of inclusion. ${ }^{37}$ It seems to me time to examine more closely the range of self-representation exhibited by texts both within and across such critical categories. This project is historicist in that it honors the racial and cultural distinctions that underwrite, in part, the impulse toward self-formation in the writings of Jewish American, Chicana, and African American women, but it is more concerned with outlining the range of strategies particular narratives employ than it is in developing a general argument about a tradition of women's autobiography. My interest is in analyzing the strategies women with little access to textual positions 
of authority use to develop their voices, and, in keeping with this privileging of the will to autobiographical presence, I have tried to approach selected narratives as "agents as well as effects of cultural change," to adopt the phrase Carolyn Porter uses in her critique of the New Historicism. ${ }^{38}$ In practice this has meant a focus more on the particular than on the general; a concern less with finding a textual common denominator than with considering the range of rhetorical patterns distinct narratives provide and with redefining what constitutes writing about the self-always with an eye toward the discursive and historical contexts in which such scripting is conceived, produced, and read.

\section{Cultural Engagement and Autobiographical Practice}

Cogewea then told of an amusing incident. . . The irrepressible camera man was there and he thought to obtain a rare picture of a band of stampeding buffaloes, bearing directly down upon him. He secured his negative alright, but with lowered horns the animals charged and he had scant time to spring into the branches of a nearby tree, where he hung, thus narrowly escaping with his life. A noted "Cowboy Artist" was in close proximity and he drew a sketch of the discomfited man swinging to [sic] the tree with the rushing buffaloes passing under him. It was, perhaps, a more interesting picture than the camera could have secured.

Mourning Dove, Cogewea, the Half-Blood: A Depiction of the Great Montana Cattle Range

Often, locating the personal pronoun in cultural terms means writing it in an ethnographic language that appears self-defeating. Yet like the "amusing incident" relished by Cogewea in which an aspiring ethnographer finds himself caricatured by the "half-blood" cowboys whose way of life he expects to memorialize ${ }^{39}$ the anecdotes and memories related by the women of this study often encode criticisms of the ethnographic scripts they appear to underwrite. Consider Cleofas Jaramillo, caustic on the subject of "Americans" who reproduce "Spanish" recipes without including all the ingredients necessary to make them edible; while furthering the commodi- 
fication of nuevomexicano culture, she demands that it be orchestrated by Mexicanos themselves. Or Onnie Lee Logan, whose invocations of the editorial apparatus surrounding the telling of her story elide and call attention to the heavy-handed supervisory strategies by which two kinds of self-appointed "midwives"--medical and literary-seek to control her work. Or Rose Schneiderman, whose warmest recollections serve to reconfigure the insistently Jewish family life that is being whitewashed by the commercial frame within which her narrative of union labor is published.

At their most successful, the speakers and writers considered here maneuver between autobiographical and political-cultural texts, between " $\mathrm{T}$ " and various forms of "we." This study, then, documents those impulses toward self-presencing that counterpoint as well as contravene the pressures ethnographic discourse exerts upon autobiographers. In part, what enables such autobiographers simultaneously to represent culture and to write the self is their insistence on the work involved in both activities. Focusing on the reproduction of culture as a conscious labor rather than as "something ... often unsuccessfully repressed or avoided," 40 they often stress the extent to which the traditions of their particular communities have been appropriated by others-and therefore need to be reinterpreted by themselves. In an essay on African American women's autobiography, Elizabeth Fox-Genovese has suggested that "to write the account of one's self is to inscribe it in a culture that for each of us is only partially our own," ${ }^{41}$ but if they recognize the sociopolitical stakes involved in producing life history, these autobiographers are not content to cede discursive authority to cultural outsiders. And in the process of insisting that they retain the rights to represent cultural practice, such writers confer upon themselves the status to argue their claims. Cultural critique, that is, gives them their opportunity, as women, to speak at all. In voicing their opinions about a collective with which they are affiliated, whether they broadcast these opinions or argue them sotto voce, they accord themselves the agency and presence necessary for autobiographical distinction. ${ }^{42}$

Michael Omi claims that "where political opposition was banned or useless ... transformation of the racial order, or resistance to it, was perforce military." 43 Yet the quiet but none the less decisive cultural engagement Evelyn Nakano Glenn describes suggests that this formulation is too narrow. According to Glenn, Japanese and Japanese American women acted not only as "conservators" but also as "mediators" of cultural change in the 
United States: "Employed women, especially those working as domestics, helped introduce selected aspects of American culture, such as home decoration and living arrangements." ${ }^{44}$ Making changes in home decoration may seem a modest exercise of authority, but in an environment that is less than encouraging of self-articulation and that provides almost no leisure in which to create on a grander scale, that it happens at all is telling.

The recognition that Japanese American women can articulate a cultural polemic through their domestic practices demands a rethinking of the distinction between public domain and private sphere more generally and points toward the necessity of historicizing the private as thoroughly as the public. Yet postmodern theorists have denied the political efficacy of such resistive articulations. Fredric Jameson, for instance, mourns the apparent failure of all cultural critique: "Not only punctual and local countercultural forms of cultural resistance and guerrilla warfare but also even overtly political interventions ... are all somehow secretly disarmed and reabsorbed by a system of which they themselves might well be considered a part, since they can achieve no distance from it." 45 The problem with such a systemic formulation, however, is that it denies the very real authority of individual agency-or it assumes a model of consciousness that credits its subjects with a singular incapacity to accommodate their speech to their listeners or to "speak out of both sides of their mouths" at once. ${ }^{46}$ But, as the coded critique of Rose Pesotta, the ethnographic circumlocutions of Zora Neale Hurston, and the rhetorical wiliness of VertaMae Smart-Grosvenor's formulations of identity ${ }^{47} \multimap$ or even, to cite an older illustration of such strategizing, the Trojan Horse-make clear, resistance is often most potent when it is masked, most effective when it is formulated using the language of accommodation.

In order to evaluate the political work redefining culture does for personal narrative, we need a more nuanced conception of identity. Just as autobiography critics need not reduce the relation between distinction and affiliation to an either/or equation, identification of structural principles does not have to make individual lives irrelevant. Racial identity is, after all, as Michael Omi characterizes it, composed of a "complex of individual practices.... The panoply of individual attributes-from one's patterns of speech or tastes in food or music to the economic, spatial, familial, or citizenship 'role' one occupies-provides the essential themes for political organization." ${ }^{48}$ Likewise, culture need not be formulated as an apocalyp- 
tic struggle between conqueror and conquered, but can instead be seen as a network of relations--hierarchically striated and often at odds, yes, but providing intellectual and spiritual sustenance nonetheless. As theorist John Brenkman articulates this: "Individuals ... are members of several interlaced collectivities, so that their social identities are formed by and their discursive participation occurs within several potentially conflicting cultural practices/traditions at once." 49

The narratives of the Jewish labor organizers discussed in chapters 5 and 6 display a particularly curious working out of ethnic identity. In this instance, the language of class speaks on behalf of culture as well. Published during the First World War, when to act "American" meant to choose between a very limited number of cultural scripts, many Jewish writers-Elizabeth Hasanovitz, for instance, whose autobiography was initially serialized by The Atlantic Monthly in 1917 and 1918, and Rose Cohen, whose personal narrative was published in 1918 as part of George $\mathrm{H}$. Doran Company's American Immigration Library-were able to construct American selves only by disaffiliating themselves from a Jewish culture identified as a political anachronism. In these books and others like them, the "Americanization" of the self, which requires a renunciation of Jewishness, is overtly framed as a story of class rise. Rose Pesotta's history of her involvement with the International Ladies' Garment Workers Union, Bread upon the Waters (1944) and Rose Schneiderman's recollections of struggle in All for One (1967) are equally class-conscious, but here working-class affiliations are celebrated rather than denied. In turn-of-the-century Russia, after all, to agitate for labor reform was virtually to announce yourself as Jewish-identified, since a disproportionately high number of Russian socialists were Jewish. This association, coupled with the fact that Jewish culture in the United States has historically been a working-class culture, suggests that those writers who choose steadfastly to represent themselves as part of the working poor express a kind of filial piety in the process. If there appears to be little explicit focus on Jewishness in these books, holding on to a working-class identity nonetheless enables these writers to maintain a secular kind of Jewish cultural practice.

What I wish to suggest by emphasizing the multiple and shifting nature of cultural forms and collective affiliations is that the identity that is predicated upon them is equally particularized. Its articulation takes different 
forms in different contexts, so that at various points in a narrative the same autobiographical subject may provide us with multiple formulations of, for instance, racial identity. The ethnic "I" of VertaMae Smart-Grosvenor's culinary autobiography Vibration Cooking, for example, provides readers with what would be theorized as both essentialist and constructionist conceptions of blackness. Such apparently contradictory conceptions are a problem only when we consider race or other determinants of identity as "pure" categories. Dispense with this kind of abstraction, and what looks like inconsistency soon begins to read as flexibility, the kind of flexibility that allows for a richer conception of the "I" and a more nuanced version of the self's relation to ethnicity.

Smart-Grosvenor's refusal to generalize about racial identity —or, more specifically, her insistence on providing readers with multiple generalizations-is illustrative here. Denying both ethnography's claims on the subject as "representative" and an autobiographical model which would deprive the self of racial identity, she insists: "I don't have culinary limitations because I'm 'black.' On the other hand, I choose to write about 'AfroAmerican' cookery because I'm 'black' and know the wonderful, fascinating culinary history there is. And because the Afro-American cook has been so under-appreciated." Announcements like this one pull the complacent reader up short by making any easy formulation of race impossible. Or consider the following remark in which the autobiographer's insistence on her self-distinction is framed using a language that locates this idiosyncratic "I" squarely within black speech traditions: "Black people been eating that traditional New Year's Day dinner for years. That's why I'm not having no more open house on New Year's Day. I'm going to try something new" (4).

Ethnic identity may be a constant, but its forms are constantly changing, since this particular relationship between " $\mathrm{I}$ " and "we" depends upon a number of other factors, including geography and gender, work and sexuality, generation and class status and historical circumstance. In his celebrated study of Asian American history, Ronald Takaki explains how Korean children growing up on the sugar plantations of Hawaii begin to speak pidgin more fluently than Korean, creating "a new identity associated with Hawaii," ${ }^{50}$ while in José Villareal's novel Pocho, Richard's Mexican-born father simultaneously wonders at the racism of a high school teacher and affirms his own sense of mexicanidad: "What the hell makes 
people like that, anyway? Always worried about his being Mexican and he never even thought about it, except sometimes, when he was alone, he got kinda funnyproud about it." 51

What all of these examples are designed to suggest is that we conceptualize race-and every other determinant of identity - not as a pure and irreducible category, but instead as formed by and informing the whole range of social, historical, political, and cultural circumstances within which the subject locates herself. Evelyn Brooks Higginbotham questions the tendency of feminist criticism to privilege gender as the single most important determinant of identity. Gender, she suggests, was for nineteenth-century American women "both constructed and fragmented by race. Gender, so colored by race, remained from birth until death inextricably linked to one's personal identity and social status. For black and white women, gendered identity was reconstructed and represented in very different, indeed antagonistic, racialized contexts." ${ }^{52}$ Her own counterprivileging of race as the more significant term of the equation runs the risk of creating different but equally significant overgeneralizations, however. As she herself indicates, any assessment of the ways in which race and gender inform identity must be framed historically. But privileging one term inevitably abstracts it in such a way as to render it ahistorical, reframing the contingent and material as a universal category that transcends the individual lives it sets out to explain.

This is not to suggest that I am interested in reinstating gender as the critical category of choice. Clearly, making "gender relations primary is to assume that they create a set of universal experiences more important than those of other inequalities," as Elizabeth Higginbotham, Maxine Baca Zinn, Lynn Weber Cannon, and Bonnie Thornton Dill maintain. ${ }^{53}$ Privileging gender in this way is "inadequate," autobiography critic Julia Watson argues, given that women's positions "with respect to ethnicity and class and their modes of self-identification are not only divergent but organized within a structure of power relations." ${ }^{54}$ While a certain number of globalizing statements are almost unavoidable in any discussion, I am more concerned to develop ad hoc, local observations about given narratives, privileging neither race nor gender as the dominant determinant of identity but instead acknowledging the range of inflections the combination of these factors-and others-can impart to different texts at different times. An ever more refined method of abstraction may be the mode of inquiry 
favored by much contemporary theory, but this study works instead toward a theory of the concrete, focusing closely on a series of individual voices and their permutations, refusing to make broad claims about autobiographical narrative by women but honoring the particular, distinct presences which the writers and speakers of individual narratives have worked so hard to achieve.

Generalizing statements are clearly useful in establishing the autonomy of particular autobiographical traditions, however. "Reading by ethnicity," as Sau-ling Wong argues, "is a necessary act of ... identity-building for those whose literatures have been rendered invisible by subsumption." 55 The distinction Elizabeth Fox-Genovese draws between personal narrative by black and by white women ("Much of the autobiographical writing of black women eschews the confessional mode-the examinations of personal motives, the searchings of the soul-that white women autobiographers so frequently adopt") ${ }^{56}$ is helpful in establishing the work of African American women as an autonomous narrative tradition that needs to be studied in its own right and on its own terms. Yet in circumscribing a given autobiographical genre, such statements run the risk of ignoring other narrative forms with which women experiment. To consider black women's writing, again, the meditations of Charlotte Forten in the journals she kept through the mid-185os comment on the Port Royal experiment and the political circumstances of the freedmen living there but also develop a voice as rigorously "soul-searching" as are the reflections of Alice James in the diary she wrote some thirty years later. Marita Golden's 1983 autobiography oscillates between ethnographic description and an analysis of the "personal motives" that drew its author to Nigeria and back home following the birth of her son and a failed marriage. And Maya Angelou's 1986 appraisal of the relations between Africans and African Americans discloses as many personal "confessions" as political critiques. ${ }^{57}$

Delineating autobiographical traditions by particular groups of women requires, of necessity, limiting them as well. When scholars begin to make generalizations about the practices of women writers as a whole, however, the drawbacks attendant upon their conclusions are potentially more serious, their summarizing claims more likely to slight a greater range of selfrepresentational strategies. The tendency of some feminist autobiography theory to celebrate the feminine self-in-relation rightly critiques the androcentric quality of much autobiography theory, but at the same time it 
leaves us with a model of the subject so abstracted as to transcend social conditions. Mary G. Mason's description, for instance, obscures as much as it reveals:

The self-discovery of female identity seems to acknowledge the real presence and recognition of another consciousness, and the disclosure of female self is linked to the identification of some 'other.' This recognition of another consciousness-and I emphasize recognition rather than difference-this grounding of identity through relation to the chosen other, seems ... to enable women to write openly about themselves. ${ }^{58}$

For a great many women, as I have suggested earlier, the relation between "recognition" and "difference" is far more complicated, writing "openly" an impossibility - even with the authority affiliation provides. Take, for instance, the records of Jewish labor organizers considered in this study. If we assume, as does Margo Culley, that women writers in general "submerge the personal in some 'larger' purposes in order to become the vehicle for conveying a message about history," ${ }^{59}$ we are likely to hear these narratives only as voice-overs for the ongoing struggles of organized labor. Acknowledging the discursive constraints under which such activists as Rose Schneiderman and Elizabeth Hasanovitz labored leads to a different reading of their memoirs, a reading which in reaccentuating context underscores quality of voice as well.

Careful scrutiny thus suggests that we transform the terms of Culley's equation, identifying Schneiderman's and Pesotta's focus on their engagement in the collective labor contest as a means of justifying their interest as autobiographical subjects. Ostensibly celebrating the power of unified struggle, such writers thereby establish a sense of their singular authority. Elizabeth Hasanovitz's One of Them: Chapters from a Passionate Autobiography invokes the united response of hundreds of workers-in order to demonstrate how their solidarity supports her individual claim as shop steward ${ }^{60}$ Rose Schneiderman documents the founding of the National Women's Trade Union League but makes this bit of union history contingent upon personal history: "And so, with the blessings of labor and laymen the National Women's Trade Union League was born, an organization which was to be the most important influence in my life." ${ }^{61}$ And Rose Cohen's autobiography Out of the Shadow compares the anonymity of one form of collective consciousness-the dispirited sense of herself as one of 
the hospital "dependents"- to the recognition that working-class community gives to her as an individual. ${ }^{62}$

Recognizing the range of autobiographical models and the rhetorical strategies used to develop them in these three narratives alone-personal histories produced under similar publishing constraints by women of the same ethnic background-should not mean that we deny their interest as texts by women. If, as feminist critic Jill Mathews asserts, "'There can be no unified history of women,' " the field of women's autobiography is only the more compelling for the number of different histories with which it does provide us. ${ }^{63}$ Acknowledging each woman's narrative as a distinct working out of the "struggle of memory against forgetting" 64 suggests the need to theorize history differently as well, as Sarah Rice does in her autobiography $\mathrm{He}$ Included Me: "Right now what we are doing is making history. You might not ever be in a book, but you are making history. History is things that happened in the past, and things that you do every day, as long as you live, that's history." 65

Fabiola Cabeza de Baca puts this another way in We Fed Them Cactus, when she glosses for us what constitute significant events in the llano country of Northeastern New Mexico:

Money in our lives was not important; rain was important. We never counted our money; we counted the weeks and months between rains.... We would remember an unusually wet year for a lifetime; we enjoyed recalling it during dry spells. Rain for us made history. It brought to our minds days of plenty, of happiness and security, and in recalling past events, if they fell on rainy years, we never failed to stress that fact. The droughts were as impressed on our souls as the rains. When we spoke of the Armistice of World War I, we always said, "The drought of 1918 when the Armistice was signed." (11-12)

In this quiet but nevertheless radical statement, Cabeza de Baca restructures the relation between history and personal narrative. Rather than being a universal organizing principle, an abstraction against which individual lives are measured, history is redefined as a contingent phenomenon, constructed, and constructed differently, by the very individual subjects it has in more scholarly philosophical accounts found wanting in authority. Accepting of the mundane as well as the monumental, investing daily life with the attention and dignity typically accorded only to the sweeping changes of governments or the rise and fall of civilizations, "history" in this 
formulation is twin to life history, not the master narrative engineered to supplant it. Explanations like Rice's and Cabeza de Baca's and responses like the one Ron Takaki records (" 'What is it you want to know?' an old Filipino immigrant asked a researcher. 'Talk about history. What's that ... ah, the story of my life ... and how people lived with each other in my time'") grant a value to private life more commonly reserved for the public sphere. ${ }^{66}$ Perhaps this awareness will make it easier not only for Gertrude Stein but also for Rose Schneiderman-and Onnie Lee Logan and Cleofas Jaramillo and Jesusita Aragón-to receive the autobiographical recognition they deserve. 
